DOI 10.37882/2223-2982.2021.07.03

\title{
ВОПРОС ОРГАНИЗАЦИОННОЙ СТРУКТУРЫ И УПРАВЛЕНИЯ РОССИЙСКИХ УНИВЕРСИТЕТОВ ХІХ В. (ПО МАТЕРИАЛАМ УНИВЕРСИТЕТСКИХ УСТАВОВ)
}

\section{QUESTION OF ORGANIZATION STRUCTURE AND MANAGEMENT OF RUSSIAN UNIVERSITIES FROM XIX CENTURY (ON BASE OF UNIVERSITY STATUTES)}

\section{S. Arkhipov \\ N. Kharchenko \\ I. Bagdasarova \\ N. Lutsenko}

Summary: Theme of this article is question on university and management structure of Russian universities from 19th century. As sources of this investigation are used Russian universities statutes from $1804,1835,1863,1884$. Also are used facts from works of S.P. Shevyryov, G.I. Shchetinina, A.I. Avrus, F.A. Petrov, A.Yu. Andreev, R.G. Eymontova. University structure (faculties, departments), professor's and teacher's association (ordinary and extraordinary professors, adjuncts, docents, private-docents, teachers of filology) are comparatively analyzed, also comparison between university position and science degree. Mechanisms of university management are specially investigated: two management bodies $f$ university - Council and Administration - and their functions and procedures of solution keeping are analyzed.

Keywords: higher education, university statutes, Russian universities.

\section{C} принятием устава 1804 г. начался новый этап развития в системе образования, в первую очередь университетского. Устав 1804 г., разработанный сначала только для Московского университета, впоследствии распространил своё действие и на другие университеты. В уставе 1804 г. дано определение, что такое есть университет. § 1. первой главы устава гласит: «Университет есть высшее учебное сословие, для преподавания наук учреждённое» [5, Гл. І. § 1]. Целью университета являлось то, что «в нём приуготовляется юношество для вступления в различные звания Государственной службы» [5, Гл. І. § 1].
Архипов Сергей Владимирович

старший преподаватель, Московский государственный университет пищевых производств

lusofon@mail.ru

Харченко Николай Леонидович старший преподаватель, Московский государственный институт физической культуры, спорта и туризма им. Ю.А. Сенкевича m-rh@mail.ru

Багдасарова Илона Юрьевна

старший преподаватель, Московский физико-технический институт (начиональный исследовательский университет) artameli@mail.ru

Лученко Наталья Станиславовна старший преподаватель, Московский физико-технический институт (национальный исследовательский университет) nataly.1@inbox.ru

Аннотация: Темой данной статьи является вопрос о структурной организации и управлении университетов России в XIX в. В качестве источников данного исследования были использованы университетские уставы 1804, 1835, 1863, 1884 гг. Кроме того, были использованы сведения из работ С.П. Шевырёва, Г.И. Щетининой, А.И. Авруса, Ф.А. Петрова, А.Ю. Андреева, Р.Г. Эймонтовой. Последовательно проводится сравнительно-сопоставительный анализ структуры университетов (количество факультетов и кафедр), штатного состава (количество ординарных и экстраординарных профессоров, адъюнктов, доцентов, приват-доцентов, учителей словесности), соотношения университетской должности и учёного звания. Отдельно исследуются механизмы управления университетами: сравниваются основные органы управления университетами - Совет и Правления, сферы их полномочий и процедуры утверждения их решений.

Ключевые слова: высшее образование, университетские уставы, российские университеты.

Уставом была определена структура университета, которая представляла собой четыре отделения (факультета), которые в свою очередь включали в себя 28 кафедр (вместо прежних десяти) [5, Гл. III. §§ 24-25]:

1. нравственных и политических наук (7 кафедр);

2. физических и математических наук (8 кафедр): при этом отделении функционирует особая кафедра натуральной истории, т.н. «Демидовская»;

3. врачебных или медицинских наук (6 кафедр);

4. словесных (7 кафедр).

Помимо факультетов при университете учреждались 
Академическая гимназия, Педагогический институт, Медицинский (Клинический, Хирургический, повивального искусства); Общество истории и древностей российских, Общество соревнования медицинских и физических наук и т.д.

По штату полагалось 28 ординарных профессоров (один профессор - одна кафедра - один предмет), 12 адъюнктов, 3 учителя иностранных языков (французского, английского, немецкого), 3 учителя «приятных искусств и гимнастических упражнений». Смысл понятия «кафедра» был заимствован из практики немецких университетов (нем. der Lehrstuhl - учебный стул), отсюда принцип один профессор - одна кафедра - один предмет: ein Professor - ein Lehrstuhl - ein Fach.

Однако уже в начале XIX в. наблюдаются отступления от этого правила: профессор Х.Ф. Маттеи и его преемник по кафедре профессор Р.Ф. Тимковский занимали две кафедры: греческой и латинской словесности [2, с. 172-173]. Несмотря на то, что количество профессоров и адъюнктов определялось, исходя из количества кафедр, увеличивать штат профессоров и адъюнктов не возбранялось [5, Гл. III. § 26].

В соответствии с Предварительными правилами Министерства народного просвещения от 24 января 1803 г. университет имел право присваивать учёные степени и назначать на должности, которым соответствовали классы Табели о рангах. Директор Департамента народного просвещения И.И. Мартынов, подчёркивая важность модели учёный - чиновник, писал: «Имя чиновника также прилично учёному, как и гражданскому чиновнику, ибо кто таковой, например, профессор, ежели не чиновник» [4, T. 1. с. 224]. Так, действующий ректор имел V класс, ординарный профессор - VII класс, адъюнкт - VIII класс; доктор - VIII класс, магистр - IX класс, кандидат - XII класс, действительный студент - XIV [9, с. 348].

Таким образом, эта мера предвосхитила выше процитированную цель университетов, прописанную в уставе 1804 г. (Гл. І. § 1.). По мнению А.Ю. Андреева, «университет задумывался и существовал как государственное учреждение. У него были прагматические цели - готовить из своих студентов образованных чиновников» [2, с. 95].

Во главе университета стоял ректор, во главе факультетов - деканы. И ректор, и деканы избирались за два месяца до истечения срока полномочий предыдущих ректора и деканов Советом университета на один год из числа ординарных профессоров [5, Гл. ІІ. §§ 13-14] (с 1809 г. срок замещения должностей ректора и декана был увеличен до трёх лет) [1, с. 21]. Ректор утверждался в должности высочайшим постановлением, декан - министром. В случае болезни, смерти или отсутствия ректора его обязанности исполнял проректор, избираемый из числа ординарных профессоров [5, Гл. ІІ. § 23]. В случае вакансии должности профессора, то профессор, ранее занимавший должность, через месяц представлял ректору кандидатуру, после чего проходили испытания кандидата [5, Гл. VI. § 60].

В обязанности адъюнктов входили помощь профессорам, их замещение в случае отсутствия, исполнение обязанностей секретарей в собрании и т. д., помимо этого они имели право голоса [5, Гл. IV. §§ 34-36]. Этим же параграфом предписывалось делать предпочтения для кандидатов в адъюнкты из российских граждан.

Действие устава 1835 г. распространялось на все университеты, за исключением некоторых пунктов в отношении Дерптского и Киевского университетов [6, Гл. І. § 10]. Они находились под покровительством императора и потому назывались императорскими, хотя уже в уставе 1804 г. Московский университет именовался императорским. Устав 1835 г. вводил новую структуру университета (три факультета), которая имела в себе сходные черты с современным университетским устройством [6, Гл. II. §§ 11-13]:

- философский; (философский факультет был учреждён по предложению профессора И.И. Давыдова) [2, с. 198];

а) 1-е отделение - словесности или историко-филологическое (9 кафедр); с 1850 г. историкофилологический факультет;

б) 2-е отделение - физико-математическое (8 кафедр); с 1850 г. физико-математический факультет;

- юридический (7 кафедр);

- медицинский (10 кафедр).

Избрание ректора и декана производилось Советом университета из ординарных профессоров на четыре года с последующим утверждением ректора императором [6, Гл. V. Отделение I. § 61], а декана - министром народного просвещения [6, Гл. V. Отделение I. § 68]. Кроме этого вводилась ещё одна выборная должность проректора, который также избирался из ординарных профессоров на четыре года и утверждался также министром [6, Гл. V. Отделение I. § 67] (в случае отсутствия, болезни, смерти ректора проректор исполнял его обязанности).

Как в уставе 1804 г., так и в уставе 1835 г. штат определялся количеством структурных подразделений университета, но его увеличение не запрещалось. Замещение одним профессором двух кафедр допускалось только в случае вынужденной вакансии кафедры и на небольшой срок [6, Гл. V. Отделение I. § 89]. Встречалась и такая ситуация, когда одну кафедру занимал не один профессор. Например, С.П. Шевырёв и И.И. Давыдов одновременно занимали кафедру российской словесности [2, с. 163]. 
Обязательным условием для кандидатов на должность ординарных, экстраординарных профессоров и адъюнктов было наличие степени доктора (для профессоров) и магистра (для адъюнкта). Профессора и адъюнкты избирались собранием и утверждались в должности министром, у которого было право по своему усмотрению замещать вакантные кафедры [6, Гл. V. Отделение II. $\S 80]$. Профессору, проработавшему 25 лет, присваивалось звание заслуженного профессора, его кафедра становилась вакантной: он мог в случае избрания ещё раз занять кафедру на 5 лет; по истечении этого срока вопрос о дальнейшей работе профессора решал министр [6, Гл. V. Отделение II. § 83]. Статус адъюнктов не изменился. Лицам, занимающим различные университетские должности, присваивались те же классы Табели о рангах, что и раньше [6, Гл. VII. Отделение II. § 127].

Устав 1863 г. так же, как и устав 1835 г. имел общероссийский статус. По уставу 1863 г. устройство университетов предполагало четыре факультета [7, Гл. ІІ. Отделение II. §§ 13-16]:

- историко-филологический (11 кафедр);

- физико-математический (12 кафедр);

- медицинский (17 кафедр);

- юридический (13 кафедр).

Примечание: в Санкт-Петербургском университете вместо медицинского был восточный факультет (9 кафедр - 9 профессоров, 8 доцентов, 4 лектора).

Устав устанавливает количество преподавателей:

- историко-филологический - 12 профессоров, 7 доцентов;

- физико-математический - 16 профессоров, 3 доцента;

- юридический - 13 профессоров, 8 доцентов;

- медицинский - 16 профессоров, 17 доцентов.

В соответствии с уставом 1863 г. ректор избирался на четыре года Советом университета из ординарных профессоров и утверждался в должности высочайшим постановлением [7, Гл. IV. Отделение III. § 27] (уже в 1860 г. выборность поста ректора была восстановлена) [12, 189], декан избирался факультетским собранием на три года из ординарных профессоров, а если их было менее трёх, то из экстраординарных с последующим утверждением министром [7, Гл. ІІ. Отделение І. § 8].

Важной особенностью устава 1863 г. стало установление семи категорий преподавателей: ординарные и экстраординарные профессора, старшие и младшие доценты, приват-доценты, лекторы, учителя искусств. Появилась новая должность независимого от профессора доцента взамен адъюнкта. Впервые в университетском уставе прописывался статус приват-доцентов. Эта должность впервые была введена в университете св.
Владимира в Киеве уставом 1842 г. по предложению С.С. Уварова. Целью такого кадрового нововведения было укомплектовать кадры нового университета.

Введение должности приват-доцентов свидетельствовало, что в российских университетах на рубеже 1850-1860-х гг. наблюдалась нехватка кадров. О том же свидетельствует то, что если по уставу 1835 г. профессор после 25-летней работы мог быть отправлен в отставку, то по уставу 1863 г. профессору после этого срока присваивалось звание заслуженного профессора и он мог продолжать преподавание [7, Гл. VII. § 80].

Профессора утверждались с представления Советов университетов министром, доценты и лекторы - попечителями учебных округов [7, Гл. VII. § 72]. Приват-доценты могли преподавать только после решения университетских советов [7, Гл. VII. § 75]. Так как оплата приват-доцентам по уставу 1863 г. осуществлялась за счёт средств университетов (гонорарная приват-доцентура), то сам институт приват-доцентуры в период между 1863 и 1884 гг. не получил широкого распространения.

Произошли изменения в порядке присвоения классов Табели о рангах: ректор получал IV класс, ординарный профессор - V, экстраординарный - VI, доцент - VII [7, Гл. XII. § 137]. Изменились требования к учёной степени для занятия должности: ординарный и экстраординарный профессор - доктор, доцент - магистр, приват-доцент - кандидат, защитивший диссертацию pro venia legendi (лат. на получение права читать лекции) [7, Гл. VII. § 68].

Устав 1884 г. сохранял обязательный характер для всех российских университетов, как это было в уставах 1835 и 1863 гг. В соответствии с уставом 1884 г. устанавливалась структура университетов (4 факультета), которая была похожа на модель 1863 г. [8, Отдел ІІІ. Гл. І. §§ 55-58]:

- историко-филологический (11 кафедр);

- физико-математический (10 кафедр);

- юридический (12 кафедр);

- медицинский (23 кафедры).

Уставом утверждался перечень преподавателей: ординарные и экстраординарные профессора, приват-доценты, лица, состоящие при учебно-вспомогательных установлениях [8, Отдел IV. Гл. III. § 97]. В уставе 1884 г., как и в предыдущем уставе, было определено количество преподавателей [8, Отдел III. Гл. І. § 60] (при необходимости их количество могло быть увеличено):

- историко-филологический - 12 ординарных и 5 экстраординарных профессоров;

- физико-математический - 12 ординарных и 5 экстраординарных профессоров;

- медицинский - 14 ординарных и 9 экстраординарных профессоров. 
В соответствии с новым уставом ректор назначался министром народного просвещения с последующим утверждением императором [5 г, Отдел II. Гл. II. § 10], декан - попечителем учебного округа с последующим утверждением министром [8, Отдел II. Гл. III. § 24] (срок полномочий ректора и декана - 4 года с возможным повторным сроком). Ректора в случае необходимости замещал старший по службе декан [8, Отдел II. Гл. II. § 21], декана - старший по званию сотрудник факультета [8, Отдел II. Гл. III. § 26]. Сохранялся запрет на замещение одним лицом двух кафедр: замещение вакансии в случае необходимости только при представлении попечителя с разрешения министра или по личному усмотрению самого министра [8, Отдел III. Гл. І. § 64].

Должность профессора предполагала обладание степенью доктора, кроме того, кандидат на должность профессора должен иметь трёхлетний стаж чтения лекций в звании приват-доцента университета или преподавателя другого высшего учебного заведения [8, Отдел IV. Гл. III. § 99]. Как и в предыдущих уставах после 25 -летней работы профессору присваивалось звание заслуженного профессора, по достижении 30-летнего стажа профессор исключался из штата преподавателей, но при желании ещё в течение 5 лет мог продолжать чтение лекции и при наличии разрешения попечителя мог занимать должности в университете: такому профессору министром, который мог продлить срок его службы ещё на 5 лет, назначалось содержание в размере 1200 р. в год [8, Отдел IV. Гл. III. §§ 105-106]. Замещение вакансии профессора осуществлялось путём избрания кандидата советом факультетов с последующим утверждением министром или же по собственному выбору министра [8, Гл. III. § 100].

Включение в штат приват-доцентов упраздняло гонорарную приват-доцентуру, предусмотренную уставом 1863 г. Приват-доцентами могли стать лица, имеющие учёные степени (согласно § 85 устава 1884 г. было две учёные степени: доктора и магистра; для медицинских факультетов только доктора), лица, имеющие степень магистра, но не защитившие диссертации pro venia legendi, профессора других высших учебных заведений [8, Отдел IV. Гл. III. § 109].

XIX век стал периодом формирования университетской структуры в России. Этот процесс имел динамичный характер потому, что Россия могла опираться на опыт Западной Европы. Вместе с тем, следует отметить, что воспринятая в России модель западноевропейского (немецкого) университета была приспособлена к российским условиям.

Основы университетского устройства в России были заложены в XVIII веке в связи с основанием Московского университета. Однако первые десятилетия университет испытывал много трудностей. К концу XVIII века назре- ла необходимость преобразований. Качественно новой страницей в истории университетов явилось принятие устава 1804 г. Благодаря этому документу и в целом университетской реформе Александра І университет пережил повторное рождение. Структурная реорганизация стала основой успешного развития университета. В результате этого мероприятия обновилась система преподавания, интенсифицировалась научная деятельность.

С принятием устава 1835 г. университетская структура приобрела современные черты, что способствовало прогрессу науки. Нововведения уставов 1863 и 1884 гг. свидетельствовали о дальнейшем научного знания (увеличение числа кафедр, расширение штата преподавателей), его дифференциации. Подводя итог, можно сказать, что несмотря на все трудности, развитие университетской структуры имело поступательный характер.

Организация управления университетами по уставу 1804 г. носит демократичный характер, как и весь устав в целом. Учреждались два управляющих органа: Совет или общее Собрание и Правление. Совет - «есть высшая инстанция по делам учебным и по делам судебным» [5, Гл. VI. § 48], который состоит из ординарных и заслуженных профессоров под председательством ректора. Ректор определял регламент заседания при согласии членов Совета [5, Гл. VI. § 58]. Регулярность заседаний - один раз в месяц, но в случае необходимости ректор мог созывать Совет больше установленного порядка [5, Гл. VI. § 49].

В сферу полномочий Совета входило: избрание ректора, профессоров, адъюнктов, почётных членов и назначение преподавателей в учебные заведения учебного округа; руководство учебным процессом; рассмотрение судебных дел, переданных из Правления [5, Гл. VI. § 54]. Решения Совета имели силу только при присутствии ректора или проректора, а также при условии преобладающего количества присутствующих членов над количеством отсутствующих [5, Гл. VI. § 49]. Баллотирование предусматривалось только при выборах и назначении на должности, определении студенческих работ для чтения в торжественном собрании и последующей публикации за счёт средств университета [5, Гл. VI. § 58]. Каждые полгода Совет представлял попечителю учебного округа рапорт о состоянии учебного процесса в учебных заведениях округа [5, Гл. VI. § 52].

Наряду с общим университетском собранием функционировало собрание факультета, решавшее факультетские вопросы; решения факультетского собрания вступали в силу только после утверждения Советом университета [5, Гл. VI. § 64].

Исполнительная, судебная власть в университете по уставу 1804 г. принадлежала Правлению [5, Гл. XIII. $\S 137]$. Сфера полномочий: хозяйственная часть, испол- 
нение бюджета (использование штатной суммы), разбор судебных дел, относящихся к студентам и преподавателям университета. Членами Правления, председателем которого был ректор, являлись деканы, синдик (чиновник для рассмотрения судебных дел, избираемый университетом), непременный заседатель, назначаемый попечителем из числа ординарных профессоров [5, Гл. XIII. § 134]. Правление ежегодно представляло отчёт о расходовании штанной суммы и Совету и попечителю на утверждение (в середине января).

Университеты по уставу 1804 г получали широкую автономию и, по словам А.И. Авруса, «обрели невиданную в тогдашней России демократию» [1, с. 21]. Действительно, университетская реформа Александра I была крупным прогрессивным шагом в складывании системы образования. Но не следует переоценивать результаты этой реформы. Как справедливо замечает А.Ю. Андреев: «Российская бюрократическая система наложила свой отпечаток и на устав университета, который во многих шагах был ограничен необходимостью их утверждения наверху и, главное, не был гарантирован от вмешательства государства в лице попечителя и министра народного просвещения в саму его внутреннюю жизнь. В уставе трудно было провести границу между благожелательной опекой над университетом со стороны попечителя (несомненно, необходимой особенно в период становления университета в новом качестве) и произвольным вмешательством в его внутренние дела» [2, с. 132].

Нововведения в области управления университетов, которые связаны с уставом 1835 г., касались в первую очередь Совета и Правления - управляющих органов университета. На это указывает хотя бы такая деталь: порядок функционирования Совета и Правления изложены в первых главах (III. и IV.), в уставе 1804 г., например, о Совете - VI глава, о Правлении - XIII.

Сфера полномочий университетского управления по уставу 1863 г. расширилась. Но следует отметить, что государство не совсем отказалось от регулирования университетской политики. Автономия университетов пере- шагнула границы, поставленные уставом 1835 г., потому что руководство государства осознало необходимость преобразований. Р.Г. Эймонтова полагает, что университетская реформа 1863 г. носит вынужденный характер: «Университетская реформа была исторгнута у самодержавия силой демократического натиска. Хотя бюрократическим инстанциям удалось устранить или ограничить наиболее радикальные новшества проекта, новый закон об университетах явился всё-таки несомненной уступкой со стороны верхов» [12, с. 183].

Деятельность Совета и Правления университета по уставу 1884 г. определялась по принципу, отражённому в уставе 1863 г. Все решения утверждались по трёхступенчатой системе: Совет, попечитель, министр: большинство решений утверждалось министром [8, Отдел II. Глава IV. § 30]. В работе Совета принимали участие только профессора. Правление, состоящее из ректора (председателя Правления) и деканов, решало, как и раньше хозяйственные вопросы: контроль за имуществом университета, распоряжение финансами. Решения Правления утверждались самим Правлением, Советом, попечителем, министром [8, Отдел. II. Глава VI. с. 41]. Министр имел право утверждать большинство решений Правления, как и в большинство решений Совета.

Система управления университетов по уставу 1884 г. была поставлена под чёткий контроль государства. Ярким доказательством этого служит то обстоятельство, что большинство решений Совета и Правления университетов вступали в силу только после утверждения их министром. Эта норма сильно ограничивала самостоятельность университетов, ставя их в сильную зависимость от попечителя и министра. Г.И. Щетинина даёт следующую характеристику уставу в области управления: «В уставе 1884 г. с наибольшей последовательностью были проведены реакционные принципы в вопросах управления. Остатки автономии университетов были уничтожены. Учёные советы и факультеты в вопросах управления были настолько скованы, что не могли своей властью перенести лекции с одного часа на другой» [10, с. 150].

\section{ЛИТЕРАТУРА}

1. Аврус А.И. История российских университетов. Саратов, 1998.

2. Андреев А.Ю. Лекции по истории Московского университета. М., 2001.

3. Андреев А.Ю. 1812 год в истории Московского университета. М., 1998.

4. Петров Ф.А. Формирование системы университетского образования в России. В 4-х тт. М., 2002.

5. Устав 1804 г. // ПСЗ. Собр. 1-е. СПб, 1830. Т. 14. № 10346.

6. Устав 1835 г. // ПСЗ. Собр. 2-е. СПб, 1836. Т. 10. № 8262.

7. Устав 1863 г. // ПСЗ. Собр. 2-е. СПб, 1866. Т. 38. № 39752.

8. Устав 1884 г. // ПСЗ. Собр. 3-е. СПб, 1887. Т. 4. № 2404.

9. Шевырёв С.П. История Императорского Московского университета, написанная к столетнему его юбилею. М., 1855. (Репринт. М., 1998). 
10. Щетинина Г.И. Университетский вопрос в 70-80 гг. ХІХ в. и университетский устав 1884 г. М., 1976.

11. Эймонтова Р.Г. Русские университеты на грани двух эпох. М., 1985.

12. Эймонтова Р.Г. Русские университеты на путях реформы. М., 1993.

○ Архипов Сергей Владимирович (lusofon@mail.ru), Харченко Николай Леонидович (m-rh@mail.ru), Багдасарова Илона Юрьевна (artameli@mail.ru), Луценко Наталья Станиславовна (nataly.!@inbox.ru).

Журнал «Современная наука: актуальные проблемы теории и практики»

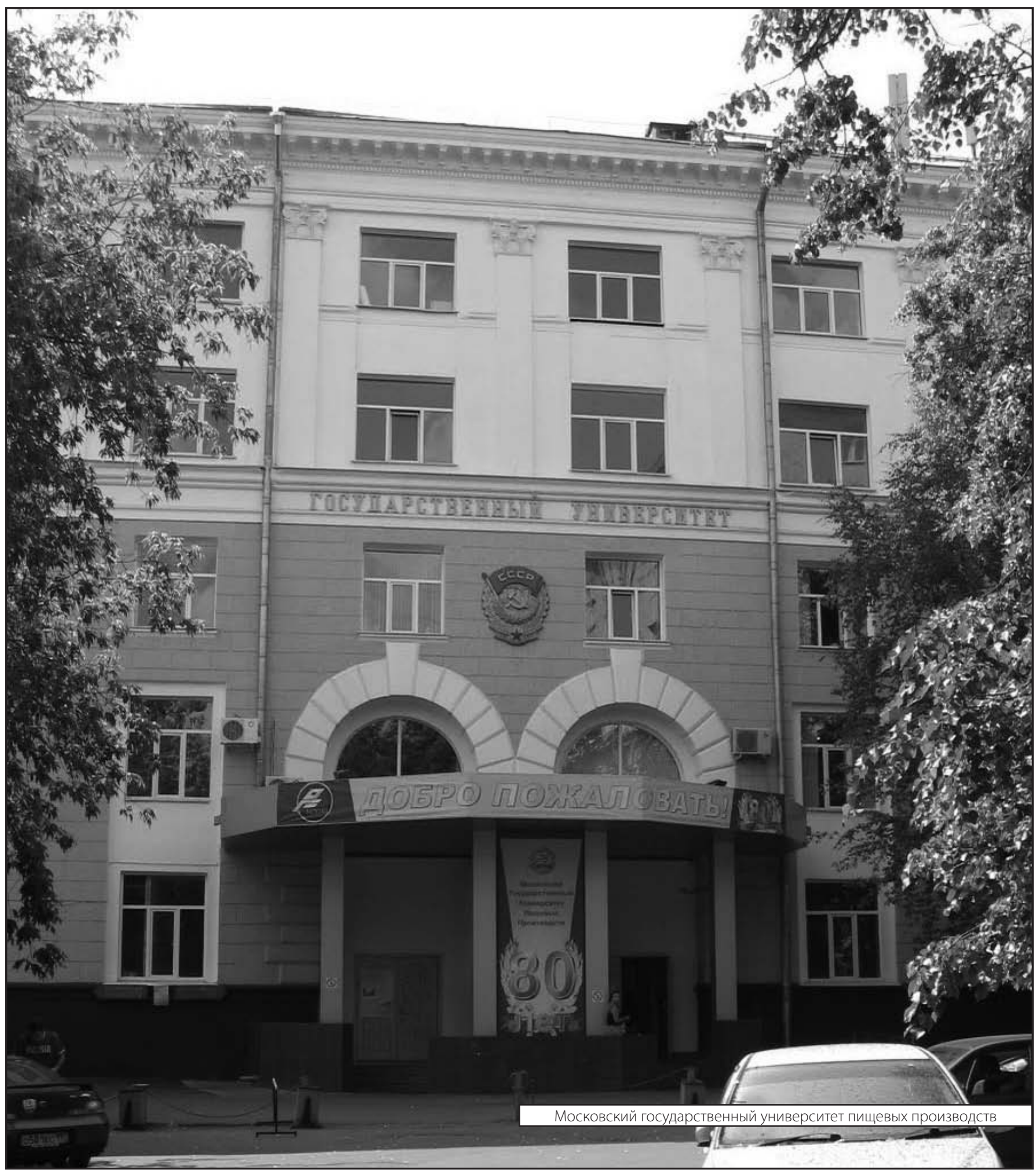

